\title{
In-vitro evaluation of a novel MR-compatible cardiac bioptome catheter for MR-guided myocardial biopsies
}

\author{
Sebastian A Seitz ${ }^{1 *}$, Sebastian M Haberkorn', Herbert Maslanka², Hugo A Katus ${ }^{1}$, Henning Steen ${ }^{1}$ \\ From 15th Annual SCMR Scientific Sessions \\ Orlando, FL, USA. 2-5 February 2012
}

\section{Background}

Retrieval of myocardial biopsies under X-ray guidance in patients with unclear myocardial dysfunction or acute myocarditis is a difficult and potentially hazardous procedure since soft tissues only offer low X-ray contrast during the procedure and extraction of biopsies could cause myocardial rupture and concomitant haemopericardium. In contrast, cardiac magnetic resonance imaging provides excellent soft-tissue and anatomic information, especially for inflamed and fibrotic areas. MR-guided myocardial biopsies would therefore be attractive but could not be performed until now due to incompatible bioptome catheters leading to substantial image artifacts and significant device heating.

Evaluation a novel MR-compatible bioptome in invitro experiments to assess potential artifacts, safety aspects and performance of MR-guided navigation under real-time imaging in a cylindrical $1.5 \mathrm{~T}$ system.

\section{Methods}

The bioptome was evaluated in a series of in-vitro experiments in an 1.5T MRI system (Philips Achieva). The specific device design (non-disclosure) avoided inducible currents and subsequent heating. The bioptome was introduced and navigated inside a) plastinated cow and swine hearts and b) a plastic heart model. The first model forms a true anatomic environment containing all relevant morphological structures (figure 1(A). The second model was derived from a human cardiac CT scan using rapid prototyping (figure 1(B)). Both phantom types were placed inside a saline filled plastic box. The MR-guidance was conducted with a

${ }^{1}$ Department of Cardiology, University of Heidelberg, Heidelberg, Germany Full list of author information is available at the end of the article continuous SSFP imaging sequence (frame rate $=2$ images/s) by visually tracking the artifact introduced by the metal element at the tip.

\section{Results}

The metal tip of the bioptome produced an artifact that allowed constant and precise ex-vivo tip localization. The artifact size was approximately $3.3 \times 3 \mathrm{~cm}$ (figure 1 (C),1(D)). The different structural elements of the heart and the target regions for the biopsy were clearly visible enabling a significantly better navigation of the tip than in conventional X-ray. The shaft of the bioptome caused no artifacts.

\section{Conclusions}

With the novel MR compatible bioptome, the superior CMR soft tissue visualization can be made available for MR-guided myocardial biopsies overcoming the limited soft tissue contrast on X-ray images. Clinically, this could significantly reduce the high amount of necessary specimen to overcome the sample error under X-ray and secondly improve the specificity and reliability of cardiac biopsies. Thirdly, MR-guided biopsies would minimize X-ray dose for the patient and especially the interventionalist.

\section{Funding}

None.

\section{Author details}

'Department of Cardiology, University of Heidelberg, Heidelberg, Germany. ${ }^{2} \mathrm{H}$. + H. Maslanka Chirurgische Instrumente GmbH, Tuttlingen, Germany.

Published: 1 February 2012 


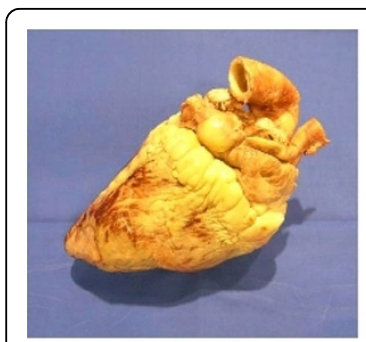

Figure A - Plastinated heart of a cow.

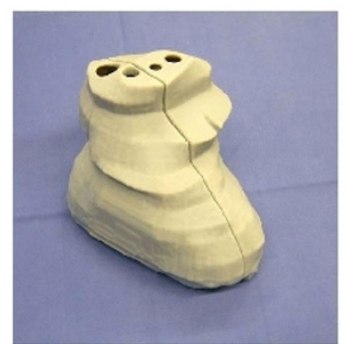

Figure B - Plastic model of a human heart.

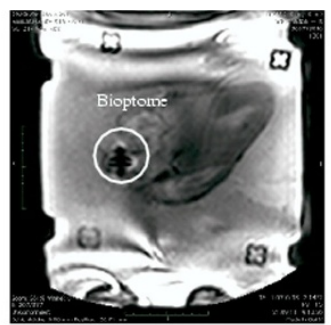

Figure C - Real time MRI image of mode shown in (A) with tip of bioptome.

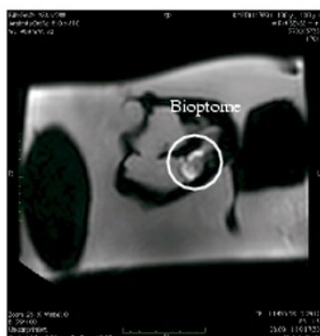

Figure D - Real time MRI image of model shown in (B) with tip of bioptome.

Figure 1

doi:10.1186/1532-429X-14-S1-032

Cite this article as: Seitz et al:: In-vitro evaluation of a novel MRcompatible cardiac bioptome catheter for MR-guided myocardial

biopsies. Journal of Cardiovascular Magnetic Resonance 2012 14(Suppl 1): O32.

Submit your next manuscript to BioMed Central and take full advantage of:

- Convenient online submission

- Thorough peer review

- No space constraints or color figure charges

- Immediate publication on acceptance

- Inclusion in PubMed, CAS, Scopus and Google Scholar

- Research which is freely available for redistribution

Submit your manuscript at www.biomedcentral.com/submit

C Biomed Central 